\title{
KEEPING TALLY WITH MEANING: \\ READING NUMERALS IN WALT WHITMAN'S MANUSCRIPTS
}

\section{MATT COHEN AND AARON DININ}

ONE OF THE GREAT GIFTS of the digital age to literary research and pedagogy is access to images of writers' manuscripts. Of particular interest is a writer like Walt Whitman, whose work is out of copyright and whose manuscripts routinely attract literary historians. Teaching or studying the development of the poem that would become "I Sing the Body Electric," for example, now requires only a copied URL if one wants to use manuscript 13 from Duke University's Trent Collection (Figure 1) for classroom discussion or source document analysis. ${ }^{1}$ This document includes a list of human body parts in many ways congruent - and fascinatingly not so-with anatomical features appearing in the published poem. In it we can see a deep framework for a section of Whitman's poem as he plays out the logic of his bodily catalog in full. But the manuscript also provokes new questions about why some elements from the draft made it into the printed poem and why others were altered or left out ("man-nuts," for example, was intriguingly displaced by "inward and outward round" in the 1856 version, while perhaps less surprisingly, "upper half leg” was left out).

But turn the document sideways, and other questions, requiring other modes of analysis, emerge. On the manuscript, scrawled between the columns, appears the number "1856" atop the number "1776," followed by a line, and then the number " 80 ." Traditional left-toright reading techniques don't easily explain how the notation-a kind found often in Whitman's manuscripts-functions in relation to the finished poetry's content, but an unconventional analytical approach can. In this case, Whitman's famous character of the old man "six feet tall" and loved by all who saw him may have been the occasion of the calculation. Whitman describes the age-enlightened farmer and father of the poem as being "over eighty years old." The 1856 number aligns with the version of Leaves of Grass that incorporates 


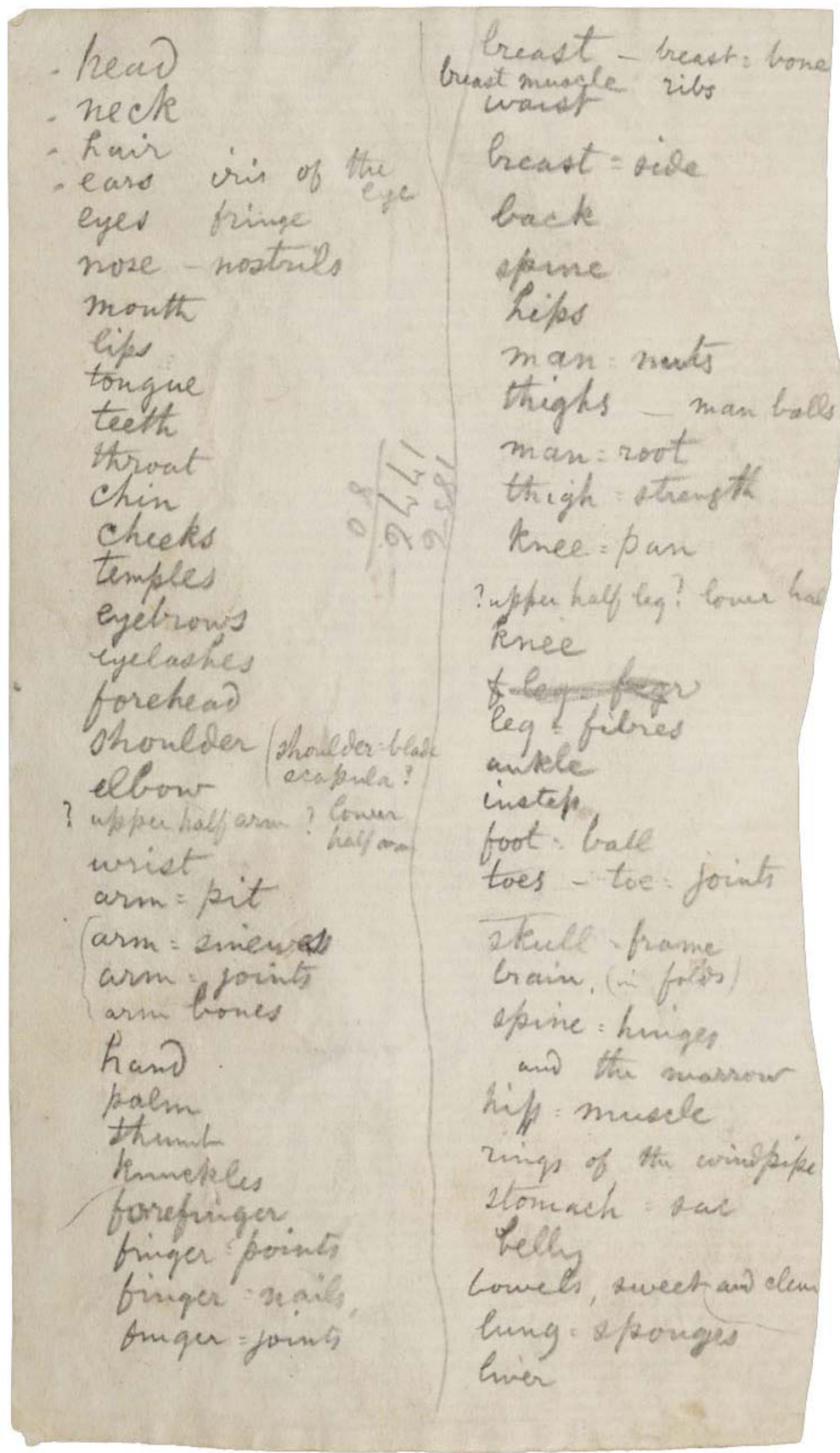

Figure 1. Figure 1. Whitman manuscript listing body parts, Trent Collection, MS 13 (Frey \#I:14, pp. 7-8), David M. Rubenstein Rare Book and Manuscript Library, Duke University. 
the first appearance of the list of body parts drawn from this manuscript, in the poem then titled "Poem of The Body." The number 1776 likely refers to the official year of United States independence from Great Britain. Whitman was trying to determine the number of years between the claiming of independence and his own historical moment of publication. He may have done so to verify that the age of the character he introduced in the poem the year before, in its 1855 version, would still bracket the country's initial moment of political democracy and Whitman's instantiation of a democratic poetic form. The vertical line dividing the page, however, curiously weaves to accommodate the mathematical notation: might this list have been written earlier, and re-consulted for the 1856 publication? Without the marginal annotation of MS 13, the eighty-year link and its attendant questions can fade as we focus on the manuscript's linguistic content. A mathematical sideways glance helps make visible a step in the process of poetic creation and the interdependence of Whitman's mathematical skill and his poetic acts of imagination.

If we take manuscripts seriously as objects of study in themselves, we can relate such digits and operations, or similar annotations, more intimately to the story of an author's world and his poetry. Though their layouts vary according to the chirographic and morphological conventions of the times in which they were made, manuscripts often contain violations or manipulations of the space of the page that, for students accustomed to printed text (and digital texts that use print conventions), can challenge interpretive norms. "Read with a . . . wandering eye," Marta Werner writes, "the draft may disturb the very idea of the still, absolute text, revealing it as only one possible realization of a matrix that precedes and sometimes follows it. Under these conditions, the draft is no longer a point of departure for the 'work,' into which it ultimately vanishes, but, rather, a witness to the 'poetics of writing."' The case of the draft of "I Sing the Body Electric" illustrates how that poetics can be not just a matter of Whitman's metaphorical "magnifying and applying," but can enfold and depend upon the seemingly prosaic work of adding and subtracting, multiplying and dividing. For U.S. readers in 1856, the mention of the old man's age might have predictably evoked the era of independence. But for 
today's students, unlikely to see that connection, this manuscript and its mathematical work illuminate such connections while, through the list of body parts, raising other questions about Whitman's compositional choices. ${ }^{3}$ Following the lead of studies of the "material text," we argue that such fractures are not ancillary, but in fact are productive disruptions or deformations that partner in the making of poetry. ${ }^{4}$

A manuscript calls for both the customary genealogical readingestablishing its place in the generation of a published text-and a contextual reading that would take the manuscript as a textual performance with its own life, one often indicative of multiple streams of a writer's development, not all of them "literary." In the case of Whitman, given his early work as a printer and journalist, as well as the way in which he circulated manuscript fragments among friends and disciples, such an integrative reading of the visual and textual elements of the page is essential to understanding the generic acrobatics demanded by his conception of page-space. In this way, too, the availability and manipulability of manuscripts in digital formats can push forward pedagogical innovation, weaving together visual, literary, and historical analysis.

"Tallying," Whitman's pervasive mathematical metaphor for the poet's task, is one of many operations the poet offers as a source of inspiration and imagery. In one manuscript, for example, Whitman discusses sub-disciplines of the sciences, suggesting to himself the composition of

Poems identifying the different branches of the sciences

Poems of Arithmetic

Mathematics

Calculations

Figures-Exactitude-

"O such themes! Equalities! / O amazement of things! O divine average!" writes Whitman in 1860 in "Proto-Leaf" (eventually "Starting from Paumanok"). Whitman's mathematical tendencies are everywhere; even his paratactic lists of places, occupations, and other elements of the American landscape may be seen in mathematically structural terms, as sets or polynomials. When we turn from such 
printed declarations to the manuscript documents in which they were drafted, the abundant numerals or arithmetic computations reveal poetic devices and intentions otherwise veiled. To aid the analysis of the sources and limits of Whitman's mathematical imagination, this essay surveys those numerals and operations found, seemingly furtively or tangentially clinging to the page, in Whitman's manuscripts. ${ }^{5}$ It then looks more closely at the question of the extent of his knowledge of contemporary mathematical operations, and examines the culture of mathematics within which Whitman lived through the lens of one of the textbooks of his early days-James B. Thomson's Practical Arithmetic (1848). "Mathematics is what its texts show it to be," cautions Travis D. Williams, and the "relation mathematics has to its enfolding culture has everything to do with how we read or misread, or accept or reject the importance of mathematics." We hope to begin to suggest the larger contours within which Whitman's use of numbers - poetic, pragmatic, or something in between - might have resonated, and some methodological pathways between numerical evidence and literary and historical arguments.

\section{A Tally of Tallies}

Numerals appear in Whitman's manuscripts for many different reasons, some of them more obvious than others. Stray markings may have had multiple uses, functioning simultaneously in two or more ways. Complicating any analysis of these markings is the ambiguity of certain operations or relations among numbers, or between the numbers and the concepts they represented. Where Whitman might be visibly subtracting the number " 13 " from " 48 ," for example, he might in fact be calculating thirteen years before the year 1848. The ambiguity of his purpose makes determining the identity of a particular group of numerals challenging, forcing us to rely on clues in the remainder of the manuscript or from his broader body of work. Do the computations use numerals found in other parts of the document? Do the numbers in the calculations appear in a published form of the manuscript, or at least a published work with which the manuscript can be linked? Is the manuscript associated with other manuscripts 
that might suggest possible relationships?

Although Whitman left an unusually large mass of original source material to work and learn from, there are, as is the case with any manuscript markings, precautions to consider. Chief among these concerns is whether a notation was in fact made by Whitman. In 1892, Whitman's literary executors dispersed many of the poet's materials, creating a many-threaded diaspora of documents. Even before their posthumous division, the poet actively circulated manuscripts among his friends and admirers. As a result, many individual documents are palimpsests of Whitman's hand and those of others. Numerical markings are particularly suspect as compared to linguistic ones. Manuscripts have sometimes been numbered by a previous owner for categorization or accounting purposes. ${ }^{7}$ Editors and librarians have occasionally made numerical annotations for their own purposes. Such traces of provenance are important to the overall story of the spread of Whitman's reputation and his place in literary canonization. Indeed, marks like these offer an entry point to a vein of interpretation not often brought into the English classroom: the relationships among collecting, archiving, and "literary" capital or the prominence of an author. Even the ways in which libraries have tallied the great tallier can help students understand the course of Whitman's establishment in the world literary marketplace. When Whitman documents are compared to those of other writers, they can also suggest some of the histories of taxonomization and document management among collectors, librarians, and archivists across the wide range of institutional contexts in which the poet's literary remains may now be found.

With these caveats in mind, a general categorization of the range of uses prevalent in Whitman manuscripts is helpful for understanding the significance of numbers in Whitman's writing. Whitman can be found doing calculations - adding, subtracting, dividing, and multiplying - in many of his manuscripts. Apparently the poet had no privileged spatial location for these operations, which can be found in any area of a manuscript: the corners, margins, and center of a printed document, or anywhere on the reverse side of a manuscript's main body of text. Calculations can appear vertically, horizontally, upside down, erased, marked over, or fractured by other text in the 
documents. Some computations use dates, while others use ages. In certain instances Whitman might be determining distances, and in others, calculating money or estimating an average number of words per printed page.

Dates frequently appear in the manuscripts, ranging from notations on the birth and death dates of literary giants to recording years of particular historical significance (and occasionally a combination of the two). In most manuscripts on which Whitman takes note of an important historical actor, whether in the margins of a printed article or in his own note-taking, he will either have recorded the birth and death dates of the figure or indicated the person's age at death. Whitman can occasionally be found computing an age after recording the birth and death dates of a historical figure. ${ }^{8}$ In these calculations one finds the poet scanning the broad reach of history for generalizable data about the ideal life-span of a writer, based on those of the famous - something like a big-data approach to divining the ideal physique and lifestyle for a great writer. In his work, this kind of operation functions in many ways: it is put to use in arguments for the relationship between a poet and national history, or making possible startling contrasts or coincidences, or increasing the drama of a characterization (as in the character of that eighty-year-old man, "the most beautiful and vigorous of the gang").

Concerning dates of historical significance, Whitman manuscripts include everything from marginal notations for the year of a particular war, to, in one instance, a series of pages outlining hundreds of historical events according to the years in which they took place. This latter document includes numerical annotations by Whitman on the borders of many pages.' Other date notations, referring to Whitman's daily schedules and work, can be traced to events in his life, and have been used by scholars such as Edwin Haviland Miller to reconstruct the poet's life chronology and even, based on his daybooks, to calculate the poet's income for the years 1876 to $1892 .{ }^{10}$ In between are markings that indicate less Whitman's attempt to generalize from the longue durée of history than a focus on the poet's historical moment. Like the manuscript of "I Sing the Body Electric" in Figure 1, they tally the timescape of America from Whitman's lifetime back to the Revolutionary War. 


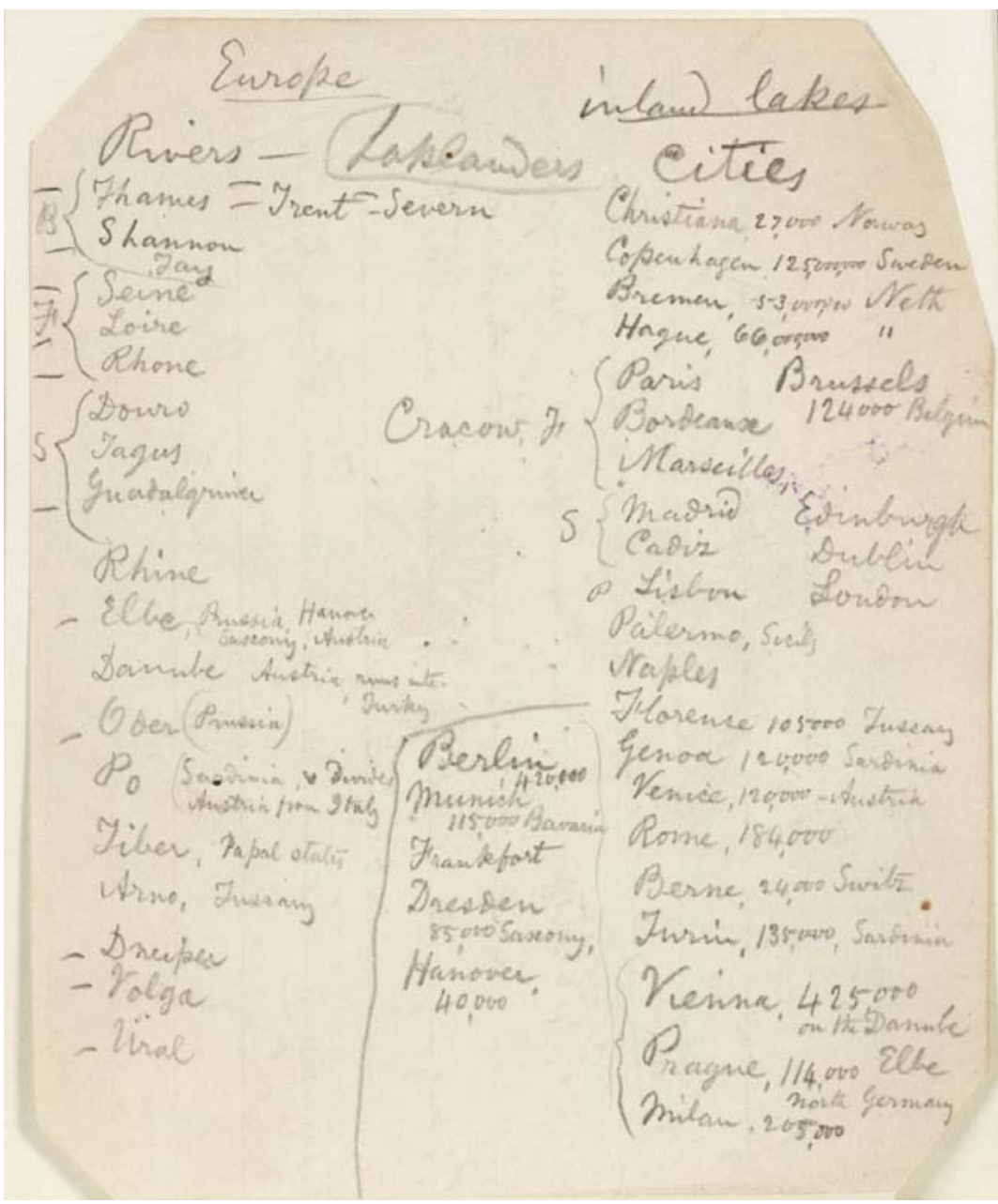

Figure 2. Whitman manuscript notes on geography and populations, Trent Collection, MS 12mo 27 (Frey \#I:33, pp. 13-14), David M. Rubenstein Rare Book and Manuscript Library, Duke University.

Whitman was preoccupied with the numerical mapping of space no less than of time and history. This concern with the spatial embraced both demography and topography (see Figure 2). Whitman's obsession with population-to-space ratios ranges from his recording of the population density of students to the number of newspapers printed by various countries. The Trent Collection's manuscript II-7 182 (Frey \#III, p. 71-73) includes two newspaper clippings on which Whitman bases a calculation. One clipping lists the number of newspapers in the 
United States by region. The other clipping includes the number of printing presses in Europe and different cities in America. Whitman takes numbers of newspapers from the different regions and adds them together for 2800; he adds the numbers given for printing presses, totaling twenty-five. Such calculations give an empirical grounding for Whitman's claims for democratic access to information in the United States and his vision of a literature equally accessible. They also, at times, give rhetorical structure both to his poetry and his prose. Memoranda During the War offers compelling examples, as Whitman joined in the statistical mode of his contemporaries, depicting the economic, environmental, and human costs of the war in sections such as "Three Years Summ'd Up" and "The Million Dead, too, summ'd up-The Unknown":

During my past three years in Hospital, camp or field, I made over 600 visits or tours, and went, as I estimate, among from 80,000 to 100,000 of the wounded and sick, as sustainer of spirit and body in some degree, in time of need.

$\cdots$

the estimate of the War Department is 25,000 National soldiers kill'd in battle and never buried at all, 5,000 drown'd-15,000 inhumed by strangers or on the march in haste, in hitherto unfound localities-2,000 graves cover'd by sand and mud, by Mississippi freshets, 3,000 carried away by caving-in of banks, \&c. ${ }^{11}$

Beneath Whitman's poetic descriptions, too, often lies a far more precise history of enumeration and calculation in manuscript. In his "Song of the Redwood Tree," Whitman cites the "long and varied stretch from Puget Sound to Colorado south." A manuscript from Trent's MS f 30 (Frey \#I:37, p. 15) reveals Whitman making notes on Puget Sound, marking that it is " 4 miles (narrow)," "10 miles (wide)," "50 miles (mountains)," "5-10 miles (riding in rain)," and contains "50-100 (couples)." Taken together, the many temporal and spatial annotations in Whitman's manuscripts suggest that the "tallying" he proposed was not limited to the space of the United States or "America," but ideally unbounded in both space and time, reaching for an understanding of his own time, place, and life-patterns within a much larger, yet in certain ways measurable, scheme.

Whitman was both a typesetter and editor. As such, perhaps 
WWQR Vol. 34 No. 2 (FALl 2016)

$$
\begin{gathered}
\text { poem (oubcit) } \\
\text { ? foetation }
\end{gathered}
$$

Aomethy which mi cark verse shale comprise

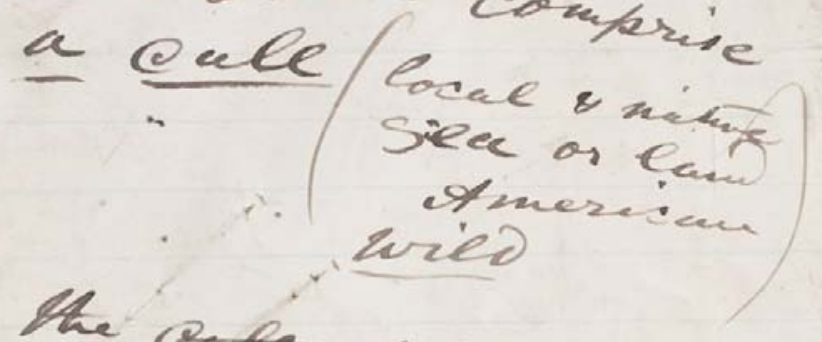

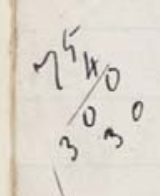

as the Gil for boy t errands lets down the taos $\mathrm{ken}$. rave the cows out of the cares. kush! Kush! Kush! as the lionises \& Colts. crekilits an car of cara una var has b hole b" the hacker peking vat of the Kayos! kapok! ky fit! or the watch at milit benghide looking ont for whales $I E H$ There-ed flow -ans.

Figure 3. Whitman manuscript notes on calls, Trent Collection, MS 18 (Frey \#I:24, p. 10), David M. Rubenstein Rare Book and Manuscript Library, Duke University.

129 
more than most poets, he was comfortable with the editorial markup of the pressroom, which appears throughout his manuscripts as he re-drafted and sent manuscripts to friends, editors, and printers for setting up in type. These notations include numeric corrections, more often than not relating to the physical structure of the poetry (such as pagination or line and page counts). Whitman constantly considered the mise-en-page as well as the overall physical structure of his books. But his manuscripts are much less controlled textual-performative spaces by comparison. Some stray marks are unrelated to the objects on which they rest. The apparent absence of relationships between these notations and the other contents of their source documents makes studying such notations particularly challenging. Often, little more than a basic chronological order can be gleaned from them. In the bottom right-hand corner of Trent MS 18 (Frey \#I:24, p. 10), the number "431" appears upside down and backwards, surrounded by unrelated sentences (see Figure 3). The significance of the notation is uncertain, though it is likely the beginning of one of Whitman's addresses in Camden, New Jersey, 431 Stevens Street. Since he was prone to writing on scraps of paper, perhaps the " 431 " represents the beginning of a letter in which Whitman was writing his address on the top left corner of the page. The multiplication of 75 by 4 on the left margin of this same document is even more difficult to contextualize.

Particularly in the case of arithmetic notations, one must be aware of the possibility for mistakes. As Williams reminds us, "to read mathematics appropriately, thoroughly, and respectfully, one must do the mathematics itself" (41). Whitman was as human as the rest of us, and he occasionally makes simple calculation errors, as in, for example, the common mistake of calculating ages before the Common Era against precedence. In Trent MS qo 187, on the edge of the inside cover of the bound document is a calculation of the lifespan of Plato, based on his age and date of death. The year 348 B.C. is annotated, "Plato the philosopher died, aged 80." At the top of the page, Whitman then writes, "Plato 268-348 B.C." In interpreting these moments of failed intention, the poet's respect for the exactitude of disciplines like mathematics should perhaps override an emphasis on his doctrine of 
the permissibility of self-contradiction. All of these cautions remind us that there is inevitably a degree of uncertainty in the interpretation of manuscript numerical annotations. The study of manuscripts is, after all, the study of historical documents, which explain themselves no more than any writing does without interpretation or contextualization.

\section{Reading Numbers}

The role of mathematics in Whitman's poetry has drawn scholarly attention. One of the poet's most pervasive tropes is "tallying"-in its most common meanings, "to score; to agree;" or to "conform." In the preface to the 1855 Leaves of Grass, Whitman writes:

The blue breadth over the inland sea of Virginia and Maryland and the sea off Massachusetts and Maine and over Manhattan bay and over Champlain and Erie and over Ontario and Huron and Michigan and Superior, and over the Texan and Mexican and Floridian and Cuban seas and over the seas off California and Oregon, is not tallied by the blue breadth of the waters below more than the breadth of above and below is tallied by him. (iv)

Tallied by him: Whitman proclaims the responsibility of the American bard with a characteristically anticlimactic metaphor. The telluric and the technological, the sublime and the mundane, stand in a relationship that makes the seemingly overwhelming totality of the United States' space democratically available for contemplation by the reader. In tallying, the poet considers and embodies all facets of America, replaces priests and presidents, and serves as a dominating and representative voice of the masses to the world and to themselves. ${ }^{12}$

From Whitman's obsessive use of lists to his additive principles of democracy to his appreciation of mathematics as a science (and thus as a model for poetry), his figurative uses of mathematical ideas have been posited as exemplary of Whitman's thorough interdisciplinarity. ${ }^{13}$ Previous examinations of the trope of tallying, for example, have tended to reduce the complex interplay of mathematical and linguistic forms of representation in favor of revealing some underlying ideological drive. For Harold Bloom, the nineteenth-century connotation of "tally" as a "sexual score" indicates a fusion of sexual and 
compositional creative energies that, in Whitman's poetry, prescribes the role of the poet as creator of a new brotherhood of man. Sex and composition, then, "first by masturbating and then by writing poems," are Whitman's fulcrum to a higher poetic vision and, Bloom implies, an "authentic American image of voice" $(49,59) .{ }^{14}$

For Alan Trachtenberg, the older, economic meaning of "tally"-a "notched stick for keeping accounts" - is more significant. "Whitman's tally," he writes, "explicates the poet's work by means of a figure which represents simple economic exchange, this for that, give and take - an exchange or conversion serving in lieu of physical money. His tally conforms to the exchange of the two halves of the marked and riven stick to establish or cancel a debt, to reach the sum of zero, of equality" (127). Ultimately, for Trachtenberg, the tally as trope calls attention to the work involved in making art; or at least, it asserts that the objects made by labor must always be thought of in terms of their connectedness to a larger world of human work. ${ }^{15}$ Though Trachtenberg's Marxist analysis implicitly deprecates Bloom's romantic nationalist concept of "voice," both analyses quickly move away from the daily world of pluses and minuses within which Whitman lived and worked. ${ }^{16}$

Such a critical gesture follows from a sense that Whitman uses science in a way succinctly summarized by David S. Reynolds as "a characteristic movement in his poetry from the scientific to the spiritual. He struggled to bring together the two in his poetry, and he made use of popular approaches that made such couplings possible." ${ }^{\prime 17}$ But more than simply coupling such ways of thinking about the world, Whitman manifestly attempts to create a method for relating disciplinary discourses and attitudes to each other through a reader's response to them. He exhibits a flexible strategy of appropriating and recalibrating the discourses of science and spirituality. Sometimes this is accomplished through a catachrestic use of terms taken from one or the other conceptual field, as in the geometrical vision of personal evolution captured by the lines "My feet strike an apex of the apices of the stairs, / On every step bunches of ages, and larger bunches between the steps." Often such an appropriation occurs simply through the use of street language, contradiction, paradox, or decontextualization, as when the geological term "cycle" is thrown out of its epochal scale 


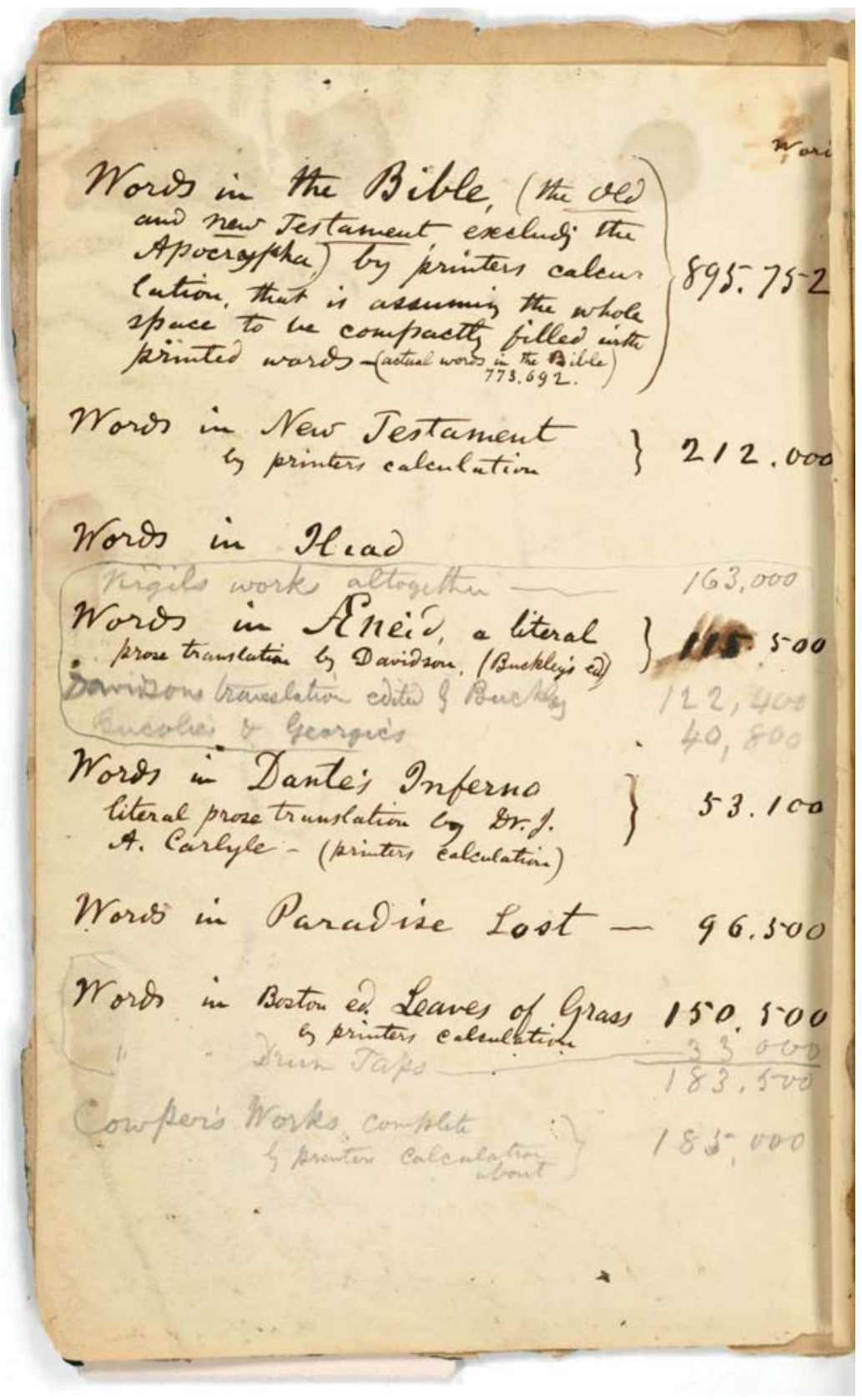

Figure 4. Front pastedown leaf in Whitman's "Blue Book," his edited copy of the 1860 edition of Leaves of Grass, New York Public Library Rare Books Collection. 
through personification: "Cycles ferried my cradle rowing and rowing like cheerful boatmen." "18 Popular mathematics texts, of course, were also more than mere "science"; Whitman's understanding of math is inseparable from his preference for a certain "democratic synthesis" approach to science. "When he was composing the first three editions of Leaves of Grass," Reynolds observes, "evolutionary and geological science was still in its pre-Darwinian phase. Scientists did not view species as combatants struggling fiercely for survival in an indifferent universe but as participants in an orderly plan visible in nature and following laws of progress" (235). Democratic union, the possibility of a social sympathy that would produce personal happiness and political cooperation (through agonistic debate), could be conceived as part and parcel of such a visible, orderly plan.

Strikingly visible in the use of numerals in his manuscripts, in Whitman's hands this formal isomorphism between the physical order and representations of it becomes a tool for thinking about even the material shape of the printed text of Leaves of Grass. Among the first few pages of the famous "blue book" (a copy of the 1860 edition of Leaves of Grass Whitman used to compose the subsequent edition) is an intriguing set of calculations (see Figure 4). In part because of his early experiences with typesetting and editing, the poet was keenly aware of and concerned with the physical appearance of the poetry on the printed page. The abstraction applied here-the "printer's calculation" of the number of words per page-is a tool for helping relate physical to poetical form. It is difficult to tell whether, by comparing the 1860 version of his text to the Bible or the complete William Cowper, Whitman was searching for a particular model or instead for what he might call a "divine average," an ideal spatial dimension for the experience of reading. ${ }^{19}$ At the least, such a meticulous comparison suggests structural concerns with how the book's printed appearance would compare to those of other prominent writers. Mathematical modeling of the physical text, not merely its discursive or spiritual content, is the bridge to relating the readerly experience of a Milton text to that of Whitman's. ${ }^{20}$

If we return to Trachtenberg's insistence on the economic origins of the metaphor, we find yet another metaphor beneath it. The philo- 
logical descendent of the broken stick-as-bond is another definition of tally - to "score" or record by scratching - that links the phrase materially to the occupation of the poet. Whitman's writings represent a figurative tallying of America through a literal, physical set of marks. In the provocative scholarship concerning Whitman and the tally, the physical presence of counting and arithmetic in his texts remains neglected, unparsed. Whitman did more than tally in his numerical markings, both in print and in manuscript, and he didn't always do it "accurately," as we might measure accuracy today. When he calculated, he did so within a social history of numerical representation that informs aesthetic interpretation. With that in mind, an important framework for "reading" Whitman's numerical inscriptions is that of the poet's mathematical background and its relation to the larger culture of mathematics in the nineteenth-century United States.

\section{American Calculations}

Horace Traubel recorded late in Whitman's life a scene of the poet "laboriously" writing out checks. ${ }^{21}$ Just how laborious was arithmetic for Whitman? Not surprisingly, there remains little specific information about the extent of Whitman's early mathematical training. Our knowledge of Whitman's early education allows us at least to suggest its outlines. His training would have consisted of basic, practical forms of calculation rooted in republican ideological goals of preparing potential small business owners, artisans, and merchants to compete in the marketplace. Whitman attended the only public school in Brooklyn from about 1825-1830. During his few years in school (he left for a job at age eleven), he was taught under what was known as the Lancastrian system of education. The Lancastrian approach, as Reynolds describes it, "emphasized rote learning and rigid discipline," offering young scholars "a basic curriculum that included arithmetic, writing, and geography." ${ }^{.22}$ The Lancastrian system was designed for use with a large number of students at a range of instructional levels. One teacher took responsibility for the education of all the students, using his or her more advanced students to teach the less advanced. Under this system, and for a length of only about five years, Whitman would 
have been taught little more than the most elementary operations of arithmetic.

Still, Whitman was an astonishing autodidact. His informal education in mathematics after his schooling, then, is no less important a consideration than his unstructured, ongoing compositional apprenticeship. He likely taught remedial mathematics during his time as a schoolteacher on Long Island in the 1830s. Katherine Molinoff considers it likely that Nathan Daboll's ubiquitous arithmetic textbook (first published in 1785) was taught by Whitman at Smithtown in 1837-38. Records also indicate that copies of Frederick Emerson's Arithmetic were requisitioned for the area's schools at around this time. ${ }^{23}$ These books covered more advanced areas of mathematics than Whitman had likely been asked to master previously. In contrast to Whitman's obvious pursuit of literary history, though, almost no evidence suggests Whitman's sustained study of arithmetic - there are no known manuscripts containing notes on mathematical formulas and equations, no sheets showing the poet practicing complex arithmetic computations.

Evidence of Whitman's sustained engagement with mathematical education comes from two articles in the Brooklyn Daily Eagle, a newspaper Whitman edited from 1845 to 1848 . In the first article, dated 21 December 1846, Whitman praises a math textbook he considers beneficial for students:

SCHOOL ARITHMETIC.-To teachers who have felt the want of good text books, (as what teacher has not?) we think we can conscientiously recommend the Practical Arithmetic, prepared by James B. Thompson [sic], and published by Mark H. Newman, 199 Broadway, N.Y. It needs but an examination and trial of its merits, to make itself its best recommendation. Can it not be put in our Brooklyn schools? ${ }^{24}$

In the second article, published on September 24, 1847, Whitman recommends three mathematics texts authored by Charles W. Hackley. He writes, "Hackley's works, the School Algebra, the Elementary course on Geometry, and the Treatise on Algebra, are all spoken of in favorable terms by mathematicians. ${ }^{\prime 25}$ Although the recommendations for mathematics textbooks seem to suggest Whitman's having 
studied arithmetic beyond his public education, no evidence definitively confirms he read them. As an editor, he might well have been paid to include these notices as "puffs"-advertisements masked as editorial commentary - which were no less important to the promotion of textbooks than to literary works. When Whitman mentions the "favorable terms" used by mathematicians to describe Hackley's work, he may be referring to the praises customarily printed in the back pages of textbooks, gathered from teachers and edited to emphasize a textbook's particular approach (just as the poet himself would do in the case of the 1856 version of Leaves of Grass). While it seems likely that, since Whitman spent approximately three years as a teacher, he came in contact with these textbooks or others like them, these works are still basic school textbooks, no more advanced than the books by which Whitman had already been taught. The most advanced of these three books, Hackley's Treatise on Algebra, stretches no further than "continued fractions" and binomial equations, two relatively simple algebraic phenomena toward the upper limit of the expectations for pre-university study in nineteenth-century America. Yet, since Whitman recommends these books - and the review of Thomson, when compared to the passive construction of the Hackley blurb, suggests he might have looked more closely at Practical Arithmetic-it seems safe to assume that he understood them at least in part.

The content of Thomson's book can be used to sketch Whitman's basic mathematics education. ${ }^{26}$ Its title, Practical Arithmetic, proclaims its functionalist goals. Thomson's lessons do not reach the territory of Hackley's third book; binomial equations would be practical for only a small audience. Instead, Practical Arithmetic begins with the definition of a number, in plain language: "Any single thing, as a peach, a rose, a book, is called a unit, or one" (13). The lessons that follow range from the four basic functions to commonly used computations such as fractions, squares, and decimal notations. After each skill is introduced, Thomson teaches a practical use for it. For example, after teaching multiplication by decimals, Thomson instructs students how to calculate interest.

Such a practical framework, and the down-to-earth style Thomson employed, were products in part of the Jacksonian era's enthusiasm 
for the democratization of public life. The examples used in the textgenerally from agricultural exchange, but including word problems with military and mercantile themes as well-position it as a public educative work designed to dovetail with instruction that idealizes productivity and expansion-oriented civic participation. Thomson's text includes a section, for example, on "Federal Money": it follows up the historical observation that "Federal Money was established by Congress, Aug. 8th, 1786" with a warning that "[m]any foreign coins are still in circulation" and the hope that the twenty-eighth Congress will abolish "these anti-national rates" (188-189). ${ }^{27}$ Such informal and opinionated comments, sprinkled throughout the text, offer by way of style a model of textbook rhetoric that fulfills in literary form what its lessons attempt to convey in content.

In addition to suggesting that Whitman's mathematical knowledge was generated within a pragmatic, democratic model, Practical Arithmetic helps illuminate aspects of the poet's notations. For example, besides missing the function signs (+, -, etc.), his subtraction problems lack the "borrowed" number used when the tens digit in the number being subtracted is greater than the tens digit of the number from which it is being subtracted. Often, when performing a computation on paper that requires borrowing, a person today may visibly show his or her borrowing calculations (such as crossing out numerals and replacing them with others). In Whitman's case, however, basic math appears to have been performed mentally. Nineteenth-century arithmeticians did not have the advantage of electronic calculators to solve complex equations quickly. To speed up problem solving, which often happened under the pressure of an economic transaction, mathematical instruction in Whitman's time emphasized constant mental calculations. Such mental work was considered integral to the broader conceptual skills mathematics instruction was meant to instill. It was also a kind of performance: the better one was at mental calculation, the less likely one's trading partner was to try to gain an advantage. After advocating mental math, Thomson scolds his readers:

Pupils not unfrequently seem to infer, that when they take up the slate and pencil, they can lay aside thinking; that the hands are to solve the question without 
the aid of the intellect. Hence operations upon the slate are often a merely mechanical effort, as listless and mindless as the talking of a parrot, or the trudging of a dray-horse. This is a sad mistake. It is sure to render the study of arithmetic irksome, and to destroy the progress of the learner. ${ }^{28}$

The frustration of the math teacher at pupils' desires to "skip steps" has only deepened, one suspects, in the digital age. There are two implications of this passage that assist our understanding of Whitman's relation to mathematics. From an analytical standpoint, just because Whitman did not write a particular number or step, we cannot eliminate the possibility that more calculations were taking place. The edges of manuscripts served as Whitman's slates, and they assisted his mental calculations. From an interpretive standpoint, such an idea-that visible material forms and invisible conceptual ones are mutually, referentially shaping-resonates with the relationship, as Whitman presents it, between poetry and the world, or more precisely among materiality, spirituality, and their mediation in writing. Whitman's struggles with mathematics and the presence of textbooks that expressly grappled with the problem of how writing things down could dull the mind may have contributed to Leaves of Grass's theorization of the relationship between the physical book and its effects on America.

"Writing," the book artist and theorist Johanna Drucker observes, "produces a visual image: the shapes, sizes and placement of letters on a page contribute to the message produced" (Drucker 146). The free availability of images and transcriptions of poetry manuscripts through internet resources such as the Walt Whitman Archive, coupled with the ongoing attention to historical context in literary studies, is changing the way poetry is taught. The fact that such documents offer the ever-present challenges of paleography and the establishment of documentary chronology will give students a chance to learn classic bibliographic techniques and some of what Rodrigo Lazo calls the "hermeneutics of archival materials" while exploring the generation of literary texts. ${ }^{29}$ But manuscripts present other challenges as well because, as Drucker hints, they often contain information irreducible 
to an eventual poetic product. They call attention to the ways in which visual layout, non-linguistic content, and even the shapes and colors of letters can shape meaning. As N. Katherine Hayles observes in her study of digital textuality, "the physical form of the literary artifact always affects what the words (and other semiotic components) mean" (Hayles 25). ${ }^{30}$

Still, as Hayles has herself observed, the rhetorics and practices of internet reading - with which students are increasingly familiar-are in many ways more like manuscript reading than like printed text. Both methods will have to partner with each other in English classrooms of the near future, but our students will often have surpassed their teachers in seeing morphological or inscriptive detail beyond the linguistic realm. We hope to have offered some first steps toward considering the mathematical dimensions of Whitman's manuscripts in a manner that does justice to the specific ways his fertile mixing of modes unfolded within and against his culture's other-than-textual practices. Even as we must defamiliarize our own ways of doing mathematics, or of thinking about its place in our culture, we open ways of seeing, in Lazo's words, "unforeseen dimensions of people's lives" and "a partial suggestion of difference that is both historical and cultural" both between us and people of the past and among those figures whom we study (181). A fuller account of how mathematics linked Whitman to his contemporaries, and of how it came to shape both his subjects and the form of his poetry, remains to be told.

University of Texas at Austin matt.cohen@utexas.edu

Duke University aaron.dinin@duke.edu 


\section{NOTES}

The authors would like to thank the staff members of the following institutions for their assistance in the researching of this essay: the University of Texas Humanities Research Center at the University of Texas at Austin, the University ofVirginia Libraries, the Library of Congress, and the Rare Book, Manuscript, and Special Collections Library at Duke University. At Duke, Elizabeth Dunn, Zack Elder, Sam Hammond, and Bob Byrd were particularly supportive of this project. Our gratitude goes also to Kenneth M. Price, Blake Bronson-Bartlett, Chris Labarthe, and Ed Folsom for comments and guidance.

1 This essay's quotations from editions of Leaves of Grass and from Horace Traubel's With Walt Whitman in Camden are taken from the editions of those works at the Walt Whitman Archive (www.whitmanarchive.org). References in parentheses are to the published catalog of the Trent Collection at Duke University: Ellen F. Frey, A Bibliography of Walt Whitman (Port Washington, NY: Kennikat $\mathrm{P}, 1965)$. For a recent reading of the role of Trent MS 13 in the early development of Whitman's poetic line, see Matt Miller, Collage of Myself: Walt Whitman and the Making of Leaves of Grass (Lincoln: University of Nebraska Press, 2010).

2 Marta Werner, “'Reportless Places': Facing the Modern Manuscript," Textual Cultures 6 (2011), 65. On the way in which manuscript was retroactively defined in relation to print and its effects on our "sense" of the two, see Peter Stallybrass, "Printing and the Manuscript Revolution," in Explorations in Communication and History, Barbie Zelizer, ed. (New York: Routledge, 2008), 111118.

3 A similar calculation appears next to another list manuscript in the same group of documents, Trent MS 13.

4 See among many others Jerome McGann, Black Riders: the Visible Language of Modernism (Princeton, NJ: Princeton University Press, 1993); Johanna Drucker, Figuring the Word: Essays on Books, Writing, andVisual Poetics (New York: Granary, 1998); the essays in Martine Reid, ed., Boundaries:Writing and Drawing, Yale French Studies 84 (1994); N. Katherine Hayles, Writing Machines (Cambridge, MA: MIT Press, 2002); and with specific reference to the practice of editing, Hans Walter Gabler and George Bornstein, eds., Contemporary German Editorial Theory (Ann Arbor: University of Michigan Press, 1995).

5 Such mathematically related configurations and notations are present in the works of other poets and literary figures; in her doctoral thesis, for example, Charlotte J. Downey presents an analysis of mathematical tropes in the poetry of Emily Dickinson. But the examples found in Whitman's works prove uncharacteristically rich from a material as well as metaphorical standpoint. See Downey, "An Application of Mathematical Reasoning to Selected Poems ofWalt Whitman and Emily Dickinson,” Ph.D. Diss. (Brown University, 1978); 
and her subsequent article, "How the Mathematical Concepts Portrayed in the Language Patterns of Walt Whitman's and ED's Poems Relate to Meaning," Dickinson Studies 72 (1989), 17-32.

6 Travis D. Williams, "Procrustean Marxism and Subjective Rigor: Early Modern Arithmetic and Its Readers," in "Raw Data" Is an Oxymoron, ed. Lisa Gitelman (Cambridge, MA: MIT Press, 2013), 41-59. See also, for a comparison to Whitman, Seo-Young Jennie Chu, "Dickinson and Mathematics," The Emily Dickinson fournal 15 (Spring 2006), 35-55.

7 Whitman made extremely economical use of paper. Hundreds of manuscripts are notes written on recycled scraps of paper, with revisions and repurposings so intense and overlaid that often, in Michael Moon's words, "the revisions and deletions are so crowded and intricate that the MS is a pastiche of line and color." As a result, non-textually linked markings may originate in a previous use of the paper, either by Whitman or by someone else. Walt Whitman, Leaves of Grass and Other Writings, Michael Moon, ed. (New York: W.W. Norton, 2002), xlv.

8 See for example the documents titled "Religions_-Gods" and "Talmud (of Jerusalem)" in the Boston Public Library's collection of Whitman MSS; and from the Trent Collection a manuscript with notes pertaining to James MacPherson and the "Ossian" controversy (Frey \#III:26, 35).

9 Trent MS qo 187 (Frey \#III, 74-75).

10 See Edwin Haviland Miller, "Introduction:Walt Whitman's Income, 18761892," The Correspondence (New York: New York University Press, 1969), xi-xxxvi.

11 Walt Whitman, Memoranda During the War (Camden, NJ: 1875), 55-56.

12 Definitions from “Tally," Webster's Handy Dictionary (New York: American Book Company, 1877), 272. These are the second meaning that Webster records, suggesting nineteenth-century awareness of the ancient practice from which the term was derived, of using a "tally" or stick with marks on it to record economic transactions. On Whitman's relationship to contemporary sciences more generally, and their role in his poetry in particular, see Robert J. Scholnick, "The Password Primeval': Whitman's Use of Science in 'Song of Myself," Studies in the Renaissance (1986): 385-425; Harold Aspiz, "'The Body Electric': Science, Sex, and Metaphor," Walt Whitman Review 24 (December 1978), 137-142; and William Gay, Walt Whitman: His Relation to Science and Philosophy (Folcroft, PA: Folcroft Library Editions, 1977 [1895]). In contexts other than his poetry, Whitman used the term "mathematical" both in a neutrally descriptive way and to deprecate an over-acute logical sensibility in either a person or an expression. See Horace Traubel, With Walt Whitman in Camden, vol. 1 (Boston: Small, Maynard, 1906), 315. 
13 For a range of arguments pivoting on Whitman's figuration of his role in relationship to denizens of the U.S., see for example Betsy Erkkila, Whitman, the Political Poet (New York: Oxford University Press, 1989); Ezra Greenspan, Walt Whitman and the American Reader (New York: Cambridge University Press, 1990); and recently, David Haven Blake, Walt Whitman and the Culture of American Celebrity (New Haven: Yale University Press, 2006).

14 Harold Bloom, "To the Tally of My Soul: Whitman's Image of Voice," The Ordering Mirror: Readers and Contexts, Phillip Lopate, ed. (New York: Fordham University Press, 1993), 42-71.

15 Alan Trachtenberg, "The Politics of Labor and the Poet's Work: A Reading of 'A Song for Occupations,"' in Walt Whitman:The Centennial Essays (Iowa City: University of Iowa Press, 1994), 120-132.

16 Debate about Whitman's use of the term precedes Bloom and Trachtenberg's philological arguments. For F. DeWolfe Miller, "tallying" describes the logic ofWhitman's long lists. Miller, "Whitman's Tally, Put at Random," Studies in Honor of fohn C. Hodges and Alwin Thaler, ed. Richard Beale Davis and John Leon Lievsay (Knoxville: University of Tennessee Press, 1961), 151-161. But for Arthur E. DuBois, the term indicates an intuitive process, not a random one. DuBois, "Keeping Whitman's Tally," Modern Language Notes 67 (June 1952), 414-417. See more recently C. Carroll Hollis, “'Tallying, Vocalizing All': Discourse Markers in Leaves of Grass," Walt Whitman: The Centennial Essays, ed. Ed Folsom (Iowa City: University of Iowa Press, 1994), 61-67.

17 Reynolds, Walt Whitman's America: A Cultural Biography (New York: Vintage, 1996), 236.

18 These two lines are taken from "Poem of Walt Whitman, an American" (which would become "Song of Myself"), in the 1856 edition of Leaves, 87.

19 That Whitman includes a correction to the equation, in the form of the actual number of words in the Bible, might seem to be in tension with the scientific methods of calculation. But it might equally be seen - given that Whitman continues to apply the printer's calculation-as an extension of that method, inasmuch as it permits a percentage correction to the subsequent calculations.

20 Similarly, in an important manuscript from the University of Texas $\mathrm{Hu}-$ manities Research CenterWhitman can be seen performing arithmetic to speculate on the 1855 edition's size by comparing the number of letters in one of his manuscript pages to the number of "letters in a page of Shakespeare's poems." See Ed Folsom, "Walt Whitman's Working Notes for the First Edition of Leaves of Grass," Walt Whitman Quarterly Review 16 (Fall 1998), 90-95. Other operations related to textual dimensions appear in Trent Collection MS 19, which includes a handwritten copy of the table of contents for the 1881-82 edition of Leaves followed by a printed copy, with calculations relating to the total number of poems and their allocation in the table of contents. 
21 Traubel, With Walt Whitman in Camden, vol. 4 (Philadelphia: University of Pennsylvania Press, 1953), 425.

22 Reynolds, ed., A Historical Guide to Walt Whitman (New York: Oxford University Press, 2000), 18.

23 Molinoff, Whitman's Teaching at Smithtown, 1837-1838 (New York: Comet Press, 1942), 18. See for example Daboll, Daboll's Schoolmaster's Assistant: Improved and Enlarged, Being a Plain Practical System of Arithmetic, Adapted to the United States (Utica: G. Tracy, 1842); Emerson, The North American Arithmetic: Part First, Containing Elementary Lessons (Boston: Lincoln \& Edmands, 1830). On the culture of accounting at this time, see Thomas Augst, The Clerks'Tale: Young Men and Moral Life in Nineteenth-Century America (Chicago: University of Chicago Press, 2003). Whitman would also have internalized the kinds of calculations that printers and compositors make in setting type during his work as a printer and journalist, as well as those of a carpenter in his later work as a real estate developer (evidenced by a range of documents held at the Library of Congress). See Peter J. L. Riley, "Leaves of Grass and Real Estate," WWQR 28 (Spring 2011), 163-187.

24 Florence B. Freedman, WaltWhitman Looks at the Schools (NewYork: King's Crown, 1950), 152-153. For more on Whitman's sustained critique of American education in the 1840s and 1850s, see Bernard Hirschhorn, "Views on Education," in Walt Whitman: An Encyclopedia, J.R. LeMaster and Donald D. Kummings, ed. (New York: Garland, 1998), 198-200. The Brooklyn Daily Eagle is available in digital form at www.brooklynpubliclibrary.org/eagle.

25 Quoted in Freedman 203. Whitman also reviewed textbooks in other disciplines around this time, such as Justus Liebig's Chemistry in Its Application to Physiology and Agriculture (1847).

26 Thomson, Practical Arithmetic, Uniting the Inductive with the Synthetic Mode of Instruction, 2nd ed. (New York: Mark H. Newman, 1848). The cover of Practical Arithmetic claims its simultaneous publication in Cincinnati, New Orleans, Auburn, and Chicago. This text was part of "Day and Thomson's Series," a group of mathematics textbooks authored or edited by Thomson (who appears to have done most of the work) and then-president of Yale University Jeremiah Day.

27 If Whitman associated his poetry with the United States' revolutionary past through the eighty-year-old man in "I Sing the Body Electric," the tactic is used even more explicitly in Thomson's text (in an exercise Whitman likely had to do himself using an earlier textbook). In the section on subtraction, a word problem teaching students to "find the time between two dates" reads: "20. The Independence of the United States was declared July 4th, 1776. How much time had elapsed on the 25th of Aug. 1845?" (165-166)

28 Thomson, Practical Arithmetic, 28. Thomson published an entire text on 
the mental method, Mental Arithmetic, in 1846. Versions of this text stayed in print and, presumably, in instructional use, until the 1890s.

29 Rodrigo Lazo, “Accounting for Textual Remains," 7192 (Spring 2014), 181.

30 Italics in the original. Hayles terms "technotexts" works that, like Whitman's, "strengthen, foreground, and thematize the connections between themselves as material artifacts and the imaginative realm" (25). 